Article

\title{
Prognostic Significance of Interim Response Evaluation during Definitive Chemoradiotherapy for Locally Advanced Esophageal Squamous Cell Carcinoma
}

\author{
Jun Gi Yeom ${ }^{1,2}$, Jie-Hyun Kim ${ }^{1, * \mathbb{C}}$, Jun Won Kim ${ }^{3, *}{ }^{\mathbb{D}}$, Yeona Cho ${ }^{3} \mathbb{D}$, Ik Jae Lee ${ }^{3}$, Chang Geol Lee ${ }^{4}$, \\ Jaeyoung Chun ${ }^{1} \mathbb{D}$, Young Hoon Youn ${ }^{1} \mathbb{D}$ and Hyojin Park ${ }^{1}$
}

1 Department of Internal Medicine, Gangnam Severance Hospital, Yonsei University College of Medicine, Seoul 06273, Korea; duawnsrl24@gmail.com (J.G.Y.); CHUNJMD@yuhs.ac (J.C.); DRYOUN@yuhs.ac (Y.H.Y.); HJPARK21@yuhs.ac (H.P.)

2 Eastern-Seoul Branch, Korea Association of Health Promotion, Seoul 07572, Korea

3 Departments of Radiation Oncology, Gangnam Severance Hospital, Yonsei University College of Medicine, Seoul 06273, Korea; IAMYONA@yuhs.ac (Y.C.); IKJAE412@yuhs.ac (I.J.L.)

4 Department of Radiation Oncology, Severance Hospital, Yonsei University College of Medicine, Seoul 03722, Korea; CGLEE1023@yuhs.ac

* Correspondence: otilia94@yuhs.ac (J.-H.K.); JUNWON@yuhs.ac (J.W.K.); Tel.: +82-2-2019-3505 (J.-H.K.); +82-2-2019-3158 (J.W.K.); Fax: +82-2-3463-3882 (J.-H.K.); +82-2-2019-4855 (J.W.K.)

\section{check for} updates

Citation: Yeom, J.G.; Kim, J.-H.; Kim, J.W.; Cho, Y.; Lee, I.J.; Lee, C.G.; Chun,

J.; Youn, Y.H.; Park, H. Prognostic Significance of Interim Response

Evaluation during Definitive

Chemoradiotherapy for Locally Advanced Esophageal Squamous Cell Carcinoma. Cancers 2021, 13, 1255. https://doi.org/10.3390/

cancers13061255

Academic Editor: Hidekazu Suzuki

Received: 22 December 2020

Accepted: 9 March 2021

Published: 12 March 2021

Publisher's Note: MDPI stays neutral with regard to jurisdictional claims in published maps and institutional affiliations.

Copyright: (c) 2021 by the authors. Licensee MDPI, Basel, Switzerland. This article is an open access article distributed under the terms and conditions of the Creative Commons Attribution (CC BY) license (https:/ / creativecommons.org/licenses/by/ $4.0 /)$.
Simple Summary: We investigated the clinical significance of interim response evaluation during definitive chemoradiotherapy in locally advanced esophageal squamous cell carcinoma. Interim response was evaluated using adaptive CT images including primary esophageal lesion and lymph node. The reduction rate of tumor area or diameter was measured. Interim response correlated with complete response and survival rates. That is, the evaluation of tumor burden reduction during treatment may help predict patient prognosis.

Abstract: The study aimed to investigate the clinical significance of interim response evaluation during definitive chemoradiotherapy (dCRT) in predicting overall treatment response and survival of patients with locally advanced esophageal squamous cell carcinoma (LAESCC). We reviewed 194 consecutive patients treated with dCRT for biopsy-confirmed LAESCC. A total of 51 patients met the inclusion criteria. Interim response was assessed by defining a region of interest in initial and adaptive computed tomography (CT) images and subsequently examined against the overall treatment response assessed three months after dCRT, treatment failure pattern, overall survival (OS), and progression-free survival (PFS) estimates. Reductions in both the area and maximal diameter of the primary lesion ( $p<0.001 ; p<0.001$, respectively) and those of the metastatic lymph nodes (LN) ( $p=0.002 ; p<0.001$, respectively) in interim analysis were significantly higher among patients who achieved complete response (CR) than among those who did not. OS was significantly longer among patients who showed $\geq 30 \%$ interim reduction in the area and maximal diameter of the primary lesion and among those who showed such reduction in both the primary lesion and LN. PFS was significantly longer in the patients with $\geq 30 \%$ interim reduction in the area of the primary lesion. In addition, the proportion of cases with locoregional failure began decreasing at interim response of $20 \%$ or higher, while the proportion of cases with outfield failure followed the opposite pattern, increasing at interim response of $20 \%$ or higher. Among patients treated with dCRT for LAESCC, interim response assessed using adaptive CT images correlated with overall CR and OS rates. The evaluation of tumor burden reduction during dCRT may help predict patient prognosis.

Keywords: esophageal cancer; definitive CRT; adaptive radiotherapy; adaptive CT; interim response 


\section{Introduction}

Esophageal cancer is the eighth most common cancer worldwide; it is associated with poor prognosis, which makes it also the sixth leading cause of cancer-related deaths [1]. Squamous cell carcinoma is the most prevalent histological subtype of esophageal cancer, while the incidence of adenocarcinoma is increasing in Western countries [2,3]. A staging system based on tumor-node-metastasis subclassification is available. However, esophageal cancers are often categorized according to the indicated treatments into early-stage superficial cancers, locally-advanced cancers with, or without, regional lymph node (LN) metastases in the absence of distant metastases, and cancers with distant metastases [4]. Patients with locally advanced esophageal cancer are a heterogeneous group that can be further divided into those with potentially resectable (T2 up to T4a) and unresectable (T4b) primary disease, poor surgical candidates, and those who decline surgery [5].

Surgery had been regarded as a standard treatment for patients with resectable esophageal cancer. However, patient outcomes remain unsatisfactory with median survival rarely exceeding 18 months [6]. Moreover, most patients are diagnosed when the disease has reached advanced or unresectable stages. Standard therapy for locally advanced esophageal squamous cell carcinoma (LAESCC) includes neoadjuvant chemotherapy or chemoradiotherapy (CRT) followed by surgery or definitive CRT (dCRT) [7]. Patients undergoing dCRT may experience local recurrence and require salvage surgery, while two-year survival rates have been reported as 31-40\% [8-10].

Adaptive radiation therapy (ART) is a mid-treatment process where the initial radiotherapy (RT) plan is modified to account for the anatomical changes in the tumor or organs at risk, aiming to deliver an accurate dose of radiation to the target while minimizing the risk of toxicity [11]. At our institution, ART consists of a second set of computed tomography (CT) scanning simulation and RT planning, usually three to five weeks into $\mathrm{dCRT}$ to accommodate anatomical changes due to tumor shrinkage. These may provide additional information regarding early (interim) treatment response. In contrast, conventional treatment response evaluation is performed one to three months after treatment completion, based on a comparison of pre- and post-treatment radiologic studies.

The present study aimed to evaluate the role of interim response evaluation during dCRT for LAESCC patients in predicting overall treatment response and survival rates. The differences in treatment failure patterns based on the interim response were also investigated.

\section{Materials and Methods}

\subsection{Patient Identification}

Patients who underwent dCRT for the treatment of locally advanced (stages II-IV) esophageal cancer at the Gangnam Severance Hospital and Severance Hospital between January 2005 and December 2018 were screened for eligibility. Only biopsy-confirmed squamous cell carcinoma cases with a measurable primary esophageal lesion on a baseline CT scan were included in the analysis. Patients were excluded from the present study if they did not undergo a CT scanning simulation for ART during dCRT or if they underwent esophageal stent insertion before or during dCRT. In general, patients underwent ART if the initial CT showed the gross tumor deviating the normal anatomy of the esophagus (usually $\geq \mathrm{T} 3$ ) and/or patients complained of symptomatic dysphagia ( $\geq$ Grade 2, CTCAE 4.0) during the initial physical examination. Among 194 patients with LAEC treated with dCRT, patients with non-squamous cell carcinoma histology, an unmeasurable primary esophageal lesion in CT, esophageal stent insertion, and no adaptive CT images were excluded. Patients were assessed by endoscopic ultrasonography, chest and abdominal $\mathrm{CT}$ scans, and ${ }^{18} \mathrm{~F}$-fluorodeoxyglucose positron emission tomography or positron emission tomography-CT (PET-CT) scans. The eighth edition of the American Joint Commission on Cancer stating system was used [4]. 


\subsection{Treatment Regimens}

All patients underwent definitive concurrent CRT. RT was performed with threedimensional conformal RT or intensity-modulated RT using conventional fractionation schedules (5 days/week, 1.8-2.0 Gy/daily fraction) and the cone-down technique at the time of ART. Gross tumor volume means primary tumor and metastatic regional LNs on images. Clinical target volume was determined as gross tumor volume plus $3 \mathrm{~cm}$ craniocaudally, $1 \mathrm{~cm}$ laterally, and $3 \mathrm{~cm}$ into the gastric mucosa in case of gastroesophageal junction tumors. A uniform $0.5-\mathrm{cm}$ expansion from clinical target volume was added to define planning target volume. The regimen of concurrent chemotherapy was mainly cisplatin and 5-fluorouracil. The dose and schedule was $75 \mathrm{mg} / \mathrm{m}^{2}$ on day 1 for cisplatin and $1000 \mathrm{mg} / \mathrm{m}^{2}$ on days $1-4$ for 5-fluorouracil, every 4 weeks in most LAESCC patients.

\subsection{Defining Regions of Interest and Interim Analysis at ART}

Contrast-enhanced initial and adaptive CT images were loaded into the Picture Archiving and Communication System software (Centricity ${ }^{\mathrm{TM}}$ PACS, GE Healthcare, Slough, United Kingdom) for the measurement of lesions. Initial CT scanning included diagnostic CT images taken at baseline and simulation CT images acquired for initial RT planning. An experienced radiation oncologist selected axial CT slices containing the primary esophageal lesion and the regional metastatic LNs with the largest diameters. In these axial CT images, regions of interest (ROIs) were manually delineated along the boundaries of tumor lesions. The area of ROI was measured including the necrotic area within the tumor, while carefully excluding adjacent fluid or air volumes or normal esophagus. The maximal diameter of esophageal cancer lesion and diameter of LN were also measured. Changes in these measurements between initial CT and adaptive CT images were calculated. An example of an ROI measuring is provided in Figure 1.

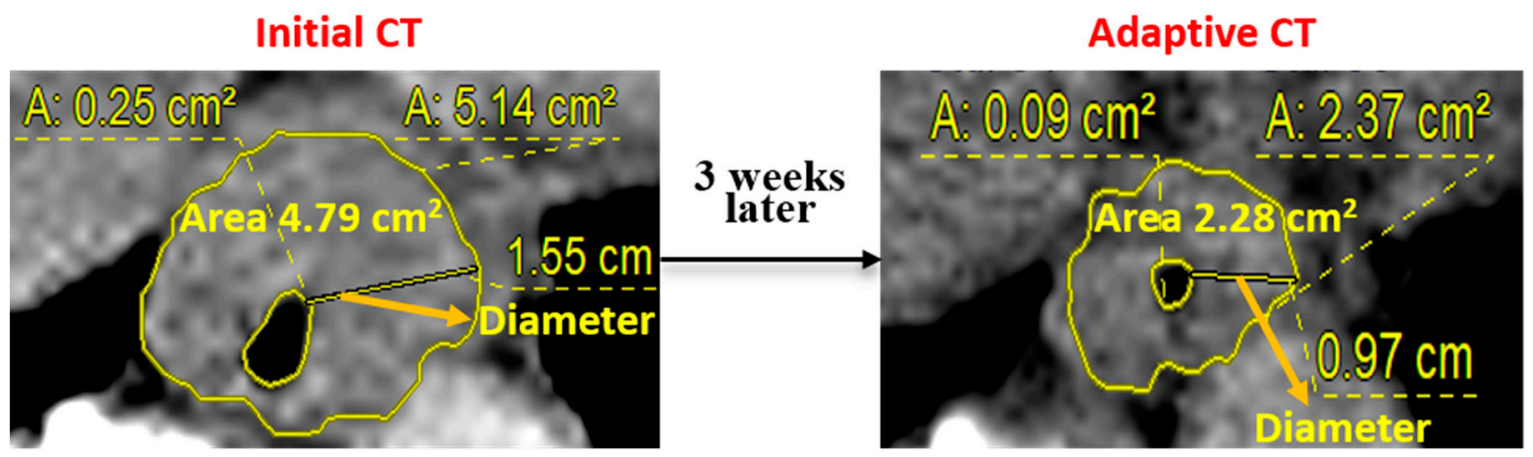

Figure 1. Measurement of region of interest (ROIs) based on initial computed tomography (CT) and adaptive CT scans. The area and maximal diameter of the esophageal lesion in the initial CT scan was $4.79 \mathrm{~cm}^{2}$ and $1.55 \mathrm{~cm}$, respectively. In the adaptive CT scan, the corresponding values were $2.28 \mathrm{~cm}^{2}$ and $0.97 \mathrm{~cm}$, respectively.

\subsection{Assessment of Overall Treatment Response}

The overall treatment response was assessed on endoscopy and chest $\mathrm{CT}$, abdominal pelvic CT, and PET-CT scans 3 months after the end of dCRT, following the Response Evaluation Criteria for Solid Tumors (RECIST) version 1.1 [12]. A complete response (CR) was defined as tumor residue not visible on endoscopy, histologic examination, chest $\mathrm{CT}$ and PET scan. CR was decided considering all examinations of endoscopy, chest CT, and PET. After dCRT for esophageal tumors, a thickening of the esophageal wall can remain in chest CT. Thus, chest CT was used mainly to evaluate CR for LN not primary lesion. To evaluate the CR for primary esophageal lesion was mainly endoscopic biopsy and PET. Gross tumor disappearance on endoscopy, no tumor cell on biopsy, and normalization of tumor FDG activity on PET were defined CR for the esophageal lesion. Treatment failure was defined as disease recurrence after achieving CR or incomplete remission after dCRT. 
Treatment failure was sub-classified into locoregional and outfield failure. Locoregional failure is a treatment failure in the esophagus or regional LN within the RT field, whereas outfield failure is a treatment failure in other areas.

\subsection{Statistical Analyses}

The index date was day of LAESCC diagnosis. All enrolled patients were followed-up until their last visit, death, or October 2019, whichever occurred first. The chi-square or Fisher's exact tests and Student $t$-tests were used to analyze statistical correlations between categorical, and non-categorical variables. Overall survival (OS) was measured from the date of diagnosis to the date of death or the date of the last follow-up visit. Progression-free survival (PFS) was measured from the date of treatment initiation until disease progression or worsening. OS and PFS were analyzed by the Kaplan-Meier method. Multivariate analysis was performed by logistic regression and Cox regression model. A $p$-value of $<0.05$ was considered significance. The IBM SPSS Statistics for Windows, Version 25.0. (Armonk, NY, USA: IBM Corp) and SAS version 9.4 (SAS Institute, Cary, NC, USA) was used for statistical analyses.

\subsection{Ethical Considerations}

The present study was performed in accordance with the Helsinki Declaration and approved by the institutional review board of Gangnam Severance Hospital (3-2018-0338). All data were de-identified and anonymized.

\section{Results}

\subsection{Baseline Characteristics of Patients}

Among 194 screened patients, 51 met the inclusion criteria, and their treatment data were analyzed. Baseline characteristics of the patients are shown in Table 1. The mean age of the patients was $65.6 \pm 9.1$ years, $43(84.3 \%)$ were male, clinical stage III was the most frequent $(31,60.8 \%)$, and most patients $(45,88.2 \%)$ received chemotherapy with the 5 -fluorouracil plus cisplatin regimen. The median total radiation dose was 6300 (4200-7200) cGy. The median follow-up duration was 16.6 (10.2-41.3) months.

Table 1. Baseline characteristics of the patients with esophageal squamous cell carcinoma receiving definitive chemoradiotherapy.

\begin{tabular}{lc}
\hline \multicolumn{1}{c}{ Characteristics } & Values $(\boldsymbol{n}=\mathbf{5 1})$ \\
\hline Age (years, mean \pm SD) & $65.6 \pm 9.1$ \\
Male $(\mathrm{n}, \%)$ & $43(84.3)$ \\
Follow up duration (months) (median, IQR) & $16.6(10.2-41.3)^{\mathrm{a}}$ \\
\hline Location $(\mathrm{n}, \%)$ & \\
Cervical & $9(17.6)$ \\
Upper & $14(27.5)$ \\
Middle & $19(37.3)$ \\
Lower & $9(17.6)$ \\
Clinical T Stage $(\mathrm{n}, \%)$ & \\
Tx ${ }^{\mathrm{b}}$ & $2(3.9)$ \\
T1 & $3(5.9)$ \\
T2 & $10(19.6)$ \\
T3 & $27(53.0)$ \\
T4 & $9(17.6)$ \\
Clinical N Stage $(\mathrm{n}, \%)$ & $4(7.8)$ \\
N0 & \\
\hline
\end{tabular}


Table 1. Cont.

\begin{tabular}{lc}
\hline \multicolumn{1}{c}{ Characteristics } & Values $(\boldsymbol{n}=\mathbf{5 1})$ \\
\hline $\mathrm{N} 1$ & $23(45.1)$ \\
$\mathrm{N} 2$ & $16(31.4)$ \\
$\mathrm{N} 3$ & $8(15.7)$ \\
Clinical M Stage, $\mathrm{n}(\%)$ & $51(100.0)$ \\
M0 & \\
Clinical TNM stage (n, \%) & $11(21.6)$ \\
Stage II & $31(60.8)$ \\
Stage III & $9(17.6)$ \\
Stage IVA & \\
Tumor histology (n, \%) & $7(13.7)$ \\
WD & $29(56.9)$ \\
MD & $7(13.7)$ \\
PD & $8(15.7)$ \\
N/A (Uncertain invasiveness) & \\
\hline Chemotherapy regimen & $45(88.2)$ \\
5-FU + cisplatin & $6(11.8)$ \\
Others ${ }^{c}$ & $27(52.9)$ \\
Consolidation chemotherapy (n, $\%)$ & $3570(2300-6300)$ \\
Adaptive RT dose, cGy [median (min-max) & $6300(4200-7200)$ \\
Total dose, cGy [median (min-max)] & \\
\hline SD, standard deviation; IQR, interquartile range; AJCC, American Joint Committee on Cancer; WD, well differ- \\
entiated; MD, moderately differentiated; PD, poorly differentiated; RT, radiotherapy. ${ }^{\text {a }}$ Follow up duration for \\
survivors was 26.2 (15.8-51.2) months. ${ }^{b}$ Unevaluable was due to the fact that EUS cannot be performed because \\
scope passing is limited. ${ }^{c}$ 5-FU + carboplatin, Docetaxel + 5-FU + cisplatin, paclitaxel + carboplatin, cisplatin \\
monotherapy.
\end{tabular}

\subsection{Interim Analysis}

The mean time interval between the initial and adaptive CT scan was approximately 1 month (30.6 \pm 7.3 days). The interim response evaluation revealed mean reduction of $33.7 \pm 24.0 \%$ in the area and $32.0 \pm 23.4 \%$ in the diameter of the primary esophageal lesion. In the case of $\mathrm{LN}, 27.2 \pm 25.1 \%$ reduction in the area and $16.6 \pm 19.2 \%$ reduction in the diameter were observed. When the interim responses of both primary tumor and LNs were combined, the mean reductions observed were $32.4 \pm 22.4 \%$ and $25.8 \pm 22.6 \%$ in the area and diameter, respectively (Table 2).

Table 2. Interim treatment response from the comparison between initial and adaptive CT images.

\begin{tabular}{|c|c|}
\hline Interim Treatment Response & Values $(n=51)$ \\
\hline $\begin{array}{l}\text { Interval between initial and adaptive CT, } \\
\text { days (mean } \pm S D \text { ) }\end{array}$ & $30.6 \pm 7.3$ \\
\hline \multicolumn{2}{|l|}{ Primary esophageal lesion } \\
\hline Initial area $\left(\mathrm{cm}^{2}\right),($ median, IQR) & $5.9(3.8-8.6)$ \\
\hline Follow up area $\left(\mathrm{cm}^{2}\right),($ median, IQR) & $4.0(2.3-5.6)$ \\
\hline Initial diameter $(\mathrm{cm})$, (median, IQR) & $1.8(1.4-2.7)$ \\
\hline Follow up diameter (cm), (median, IQR) & $1.3(0.8-1.6)$ \\
\hline Reduction of area $(\%$, mean \pm SD) & $33.7 \pm 24.0$ \\
\hline Reduction of diameter $(\%$, mean \pm SD) & $32.0 \pm 23.4$ \\
\hline \multicolumn{2}{|l|}{ LN } \\
\hline Initial area $\left(\mathrm{cm}^{2}\right),($ median, IQR) & $2.5(1.5-3.8)$ \\
\hline Follow up area $\left(\mathrm{cm}^{2}\right),($ median, IQR) & $1.7(1.1-3.3)$ \\
\hline Initial diameter $(\mathrm{cm})$, (median, IQR) & $2.1(1.7-2.5)$ \\
\hline Follow up diameter $(\mathrm{cm})$, (median, IQR) & $1.7(1.4-2.1)$ \\
\hline Reduction of area $(\%$, mean $\pm \mathrm{SD})$ & $27.2 \pm 25.1$ \\
\hline Reduction of diameter $(\%$, mean \pm SD) & $16.6 \pm 19.2$ \\
\hline
\end{tabular}


Table 2. Cont.

\begin{tabular}{lc}
\hline \multicolumn{1}{c}{ Interim Treatment Response } & Values $(\boldsymbol{n}=\mathbf{5 1})$ \\
\hline Sum of primary lesion and LN & \\
Initial area $\left(\mathrm{cm}^{2}\right),($ median, IQR) & $8.2(5.4-12.1)$ \\
Follow up area $\left(\mathrm{cm}^{2}\right),($ median, IQR) & $5.7(3.6-8.1)$ \\
Initial diameter, $($ median, IQR) & $3.3(2.1-4.8)$ \\
Follow up diameter, (median, IQR) & $2.8(1.3-3.6)$ \\
Reduction of area $(\%$, mean $\pm \mathrm{SD})$ & $32.4 \pm 22.4$ \\
Reduction of diameter $(\%$, mean $\pm \mathrm{SD})$ & $25.8 \pm 22.6$ \\
\hline SD, standard deviation; IQR, interquartile range; LN, lymph node; CT, computed tomography.
\end{tabular}

\subsection{Overall Treatment Response and Pattern of Failure}

Of 51 patients, $26(51 \%)$ showed CR 3 months after dCRT and 9 (35.6\%) showed recurrence during the follow-up period. Treatment failure, including incomplete remission and recurrence after achieving CR, were reported in 34 (66.7\%) patients. Among 34 failure cases, $16(47.1 \%)$ were locoregional (esophageal recurrence or periesophageal regional LN metastasis), 12 (35.3\%) were outfield failures, and 6 (17.6\%) were both locoregional and outfield failures (Figure 2). The lungs were the most common solid organ affected in cases of outfield failure, accounting for $9(26.5 \%)$ patients. Finally, $22(43.1 \%)$ patients were confirmed dead during the 13-year follow-up period.



Figure 2. Flow chart capturing treatment outcomes according to the clinical course. LAEC, locally advanced esophageal cancer; CRT, chemoradiotheray; SqCC, squamous cell carcinoma.

\subsection{Prognostic Significance of Interim Analysis}

Factors associated with CR are shown in Table 3. Interim responses were significantly correlated with CR. Reductions to the area and diameter of the primary esophageal lesion in the CR group were significantly higher than those in the non-CR group (18.4\% vs. $48.4 \%$, $p<0.001$, and $16.3 \%$ vs. $47.6 \%, p<0.001$, respectively). The reduction of LN area and diameter were also higher in the CR group than in the non-CR group (15.2\% vs. $40.6 \%$, $p=0.002$, and $5.8 \%$ vs. $28.7 \%, p<0.001$, respectively). The sum of area and that of diameter reduction were significantly higher in the CR group than in the non-CR group 
(17.7\% vs. $46.5 \%, p<0.001$, and $10.5 \%$ versus $40.5 \%, p<0.001$, respectively). However, there was no difference in baseline stages between the CR and non-CR group.

Table 3. Factors associated with complete response (CR).

\begin{tabular}{|c|c|c|c|}
\hline Variables & $\begin{array}{l}\text { Non-CR } \\
(n=25)\end{array}$ & $\begin{array}{c}\text { CR } \\
(n=26)\end{array}$ & $p$-Value \\
\hline Age (years, mean $\pm \mathrm{SD}$ ) & $66.4 \pm 8.0$ & $64.9 \pm 10.1$ & 0.567 \\
\hline \multicolumn{4}{|l|}{ Primary esophageal lesion } \\
\hline Initial area $\left(\mathrm{cm}^{2}\right),($ median, IQR) & $6.1(4.1-9.0)$ & $5.7(2.8-8.5)$ & 0.666 \\
\hline Reduction of area $(\%$, mean $\pm \mathrm{SD})$ & $18.4 \pm 18.0$ & $48.4 \pm 19.5$ & $<0.001$ \\
\hline Initial diameter $(\mathrm{cm})$, (median, IQR) & $1.8(1.4-2.6)$ & $1.8(1.2-2.7)$ & 0.926 \\
\hline Reduction of diameter $(\%$, mean \pm SD) & $16.3 \pm 20.4$ & $47.6 \pm 14.5$ & $<0.001$ \\
\hline \multicolumn{4}{|l|}{ LN } \\
\hline LN initial area $\left(\mathrm{cm}^{2}\right)$, (median, IQR) & $2.5(1.5-4.1)$ & $2.5(1.9-3.7)$ & 0.769 \\
\hline Reduction of LN area $(\%$, mean \pm SD) $)$ & $15.2 \pm 21.4$ & $40.6 \pm 22.4$ & 0.002 \\
\hline LN initial diameter $(\mathrm{cm})$, (median, IQR) & $2.0(1.5-2.6)$ & $2.1(1.8-2.6)$ & 0.437 \\
\hline Reduction of LN diameter $(\%$, mean \pm SD) & $5.8 \pm 14.6$ & $28.7 \pm 16.5$ & $<0.001$ \\
\hline \multicolumn{4}{|l|}{ Sum of primary lesion and LN } \\
\hline Initial Area $\left(\mathrm{cm}^{2}\right)$, (median, IQR) & $8.6(5.9-12.0)$ & $6.9(3.6-12.6)$ & 0.254 \\
\hline Reduction of area, sum $(\%$, mean \pm SD) $)$ & $17.7 \pm 17.1$ & $46.5 \pm 17.5$ & $<0.001$ \\
\hline Initial diameter $(\mathrm{cm}),($ median, IQR) & $3.3(2.6-4.4)$ & $3.3(1.9-4.8)$ & 0.618 \\
\hline Reduction of diameter, sum $(\%$, mean \pm SD) & $10.5 \pm 19.3$ & $40.5 \pm 14.4$ & $<0.001$ \\
\hline \multicolumn{4}{|l|}{ Clinical Stage (n, \%) } \\
\hline Stage II & $4(16.0)$ & $7(26.9)$ & \multirow{3}{*}{0.145} \\
\hline Stage III & $14(56.0)$ & $17(65.4)$ & \\
\hline Stage IVA & $7(28.0)$ & $2(7.7)$ & \\
\hline
\end{tabular}

SD, standard deviation; IQR, interquartile range; CR, complete response; LN, lymph node. Bold value means statistical significance because $p$ value is $<0.05$.

To determine the significance of interim response to treatment failure patterns, we analyzed data from $16(47.1 \%)$ and 12 (35.3\%) patients with locoregional and outfield failures, respectively, while excluding $6(17.6 \%)$ patients with both locoregional and outfield failures from the total of 34 patients who experienced treatment failure (Figure 2). There was no difference in the reduction of primary lesion (area and diameter) between the patients with locoregional and those with outfield failures. When the patients experiencing treatment failure were grouped by the degree of interim reduction in the area of the primary esophageal lesion from $5 \%$ to $30 \%$ in $5 \%$-increments, the proportion of cases with locoregional failure began decreasing at interim response of $20 \%$ or higher $(p=0.0501)$, while the proportion of cases with outfield failure followed the opposite pattern, increasing at interim response of $20 \%$ or higher $(p=0.0533)$ (Figure 3 ).

Figure 4 presents Kaplan-Meier curves for OS, depending on interim responses. Area and diameter reduction of the primary esophageal lesion of $>30 \%$ at interim assessment was associated with increased OS; in contrast, the area reduction of LN was not significantly associated with OS (area: $p$-value 0.001, diameter: $p$-value 0.005) (Figure 4a,b). In cases where the sum of primary esophageal cancer lesion and LN decreased by more than $30 \%$, both area and diameter showed increased survival rate (area: $p<0.001$, diameter: $p=0.014$ ) (Figure 4c). PFS was significantly longer in the patients with $\geq 30 \%$ interim reduction in the area of the primary lesion ( $p$-value 0.012) (Figure S1). Table 4 showed the multivariate analyses about CR and OS. Area reduction of the primary esophageal lesion and the sum of area reduction were significantly associated with CR and OS 


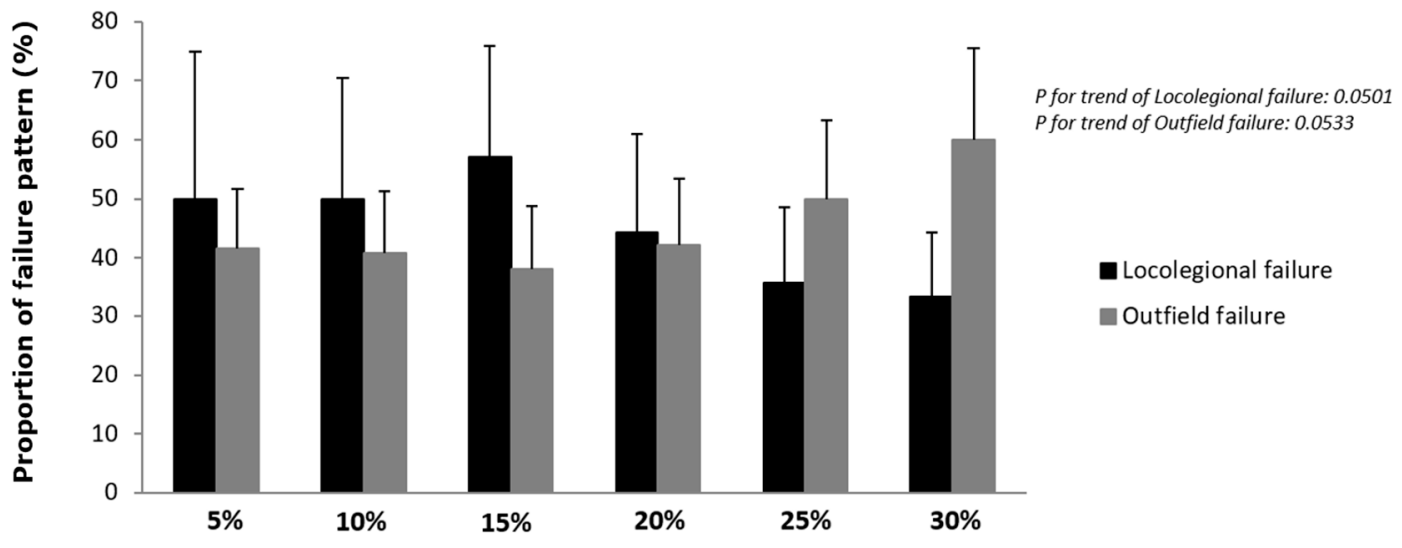

Interim treatment response threshold of area reduction in primary esophageal lesion (\%)

Figure 3. Treatment failure pattern according to the interim response during definitive chemoradiotherapy. The proportion of $y$-axis refers to the percentage of each treatment failure pattern when the treatment response of the $x$-axis is higher than that of the $x$-axis value. When the response to treatment estimate was divided by $5 \%$, the rate of local failure tended to increase by up to $15 \%$ and turned to be decreased over $15 \%$. Estimates of the outfield failure rate tended to display a pattern in the opposite direction.

Table 4. Multivariate analyses about complete response and overall survival rates.

\begin{tabular}{|c|c|c|c|c|c|c|}
\hline \multirow[t]{2}{*}{ For Complete Response } & \multicolumn{2}{|c|}{ Univariable Model } & \multicolumn{2}{|c|}{ Multivariable Model 1} & \multicolumn{2}{|c|}{ Multivariable Model 2} \\
\hline & OR(95\% CI) & $p$-Value & OR(95\% CI) & $p$-Value & OR(95\% CI) & $p$-Value \\
\hline Age & $1.02(0.96-1.08)$ & 0.559 & & & & \\
\hline \multicolumn{7}{|l|}{ Primary esophageal lesion } \\
\hline Reduction of area & $0.90(0.84-0.95)$ & $<0.001$ & $0.88(0.78-0.99)$ & 0.029 & & \\
\hline Reduction of diameter & $0.91(0.87-0.96)$ & $<0.001$ & & & & \\
\hline \multicolumn{7}{|l|}{ Lymph node (LN) } \\
\hline Reduction of area & $0.95(0.91-0.99)$ & 0.008 & $0.97(0.92-1.03)$ & 0.304 & & \\
\hline Reduction of diameter & $0.91(0.85-0.97)$ & 0.004 & & & & \\
\hline \multicolumn{7}{|l|}{ Sum of primary lesion and LN } \\
\hline Reduction of area, sum & $0.90(0.85-0.95)$ & $<0.001$ & & & $0.89(0.84-0.95)$ & $<0.001$ \\
\hline Reduction of diameter, sum & $0.88(0.81-0.94)$ & $<0.001$ & & & & \\
\hline \multicolumn{7}{|l|}{ Clinical Stage (ref: Stage II) } \\
\hline Stage III & $1.44(0.35-5.95)$ & 0.386 & $2.79(0.20-39.80)$ & 0.962 & $2.42(0.38-15.25)$ & 0.764 \\
\hline Stage IVA & $6.12(0.83-45.02)$ & 0.064 & $\begin{array}{c}8.79(0.14- \\
544.29)\end{array}$ & 0.374 & $\begin{array}{c}9.62(0.71- \\
130.07)\end{array}$ & 0.118 \\
\hline \multirow[t]{2}{*}{ For Overall Survival Rates } & \multicolumn{2}{|c|}{ Univariable Model } & \multicolumn{2}{|c|}{ Multivariable Model 1} & \multicolumn{2}{|c|}{ Multivariable Model 2} \\
\hline & $\mathrm{HR}(95 \% \mathrm{CI})$ & $p$-Value & $\mathrm{HR}(95 \% \mathrm{CI})$ & $p$-Value & $\mathrm{HR}(95 \% \mathrm{CI})$ & $p$-Value \\
\hline Age & $0.99(0.94-1.03)$ & 0.54 & & & & \\
\hline \multicolumn{7}{|l|}{ Primary esophageal lesion } \\
\hline Reduction of area & $0.98(0.97-0.99)$ & 0.001 & $0.98(0.96-0.99)$ & 0.002 & & \\
\hline Reduction of diameter & $0.97(0.95-0.99)$ & $<0.001$ & & & & \\
\hline \multicolumn{7}{|l|}{ Lymph node (LN) } \\
\hline Reduction of LN area & $0.99(0.96-1.01)$ & 0.253 & & & & \\
\hline Reduction of LN diameter & $0.97(0.94-1.00)$ & 0.07 & & & & \\
\hline \multicolumn{7}{|l|}{ Sum of primary lesion and LN } \\
\hline Reduction of area, sum & $0.97(0.96-0.99)$ & $<0.001$ & & & $0.97(0.95-0.99)$ & 0.001 \\
\hline Reduction of diameter, sum & $0.97(0.96-0.99)$ & $<0.001$ & & & & \\
\hline \multicolumn{7}{|l|}{ Clinical Stage (ref: Stage II) } \\
\hline Stage III & $0.75(0.25-2.19)$ & 0.594 & $0.58(0.19-1.79)$ & 0.346 & $0.65(0.22-1.98)$ & 0.454 \\
\hline Stage IVA & $2.29(0.72-7.30)$ & 0.16 & $1.70(0.53-5.50)$ & 0.373 & $1.84(0.57-5.90)$ & 0.308 \\
\hline
\end{tabular}



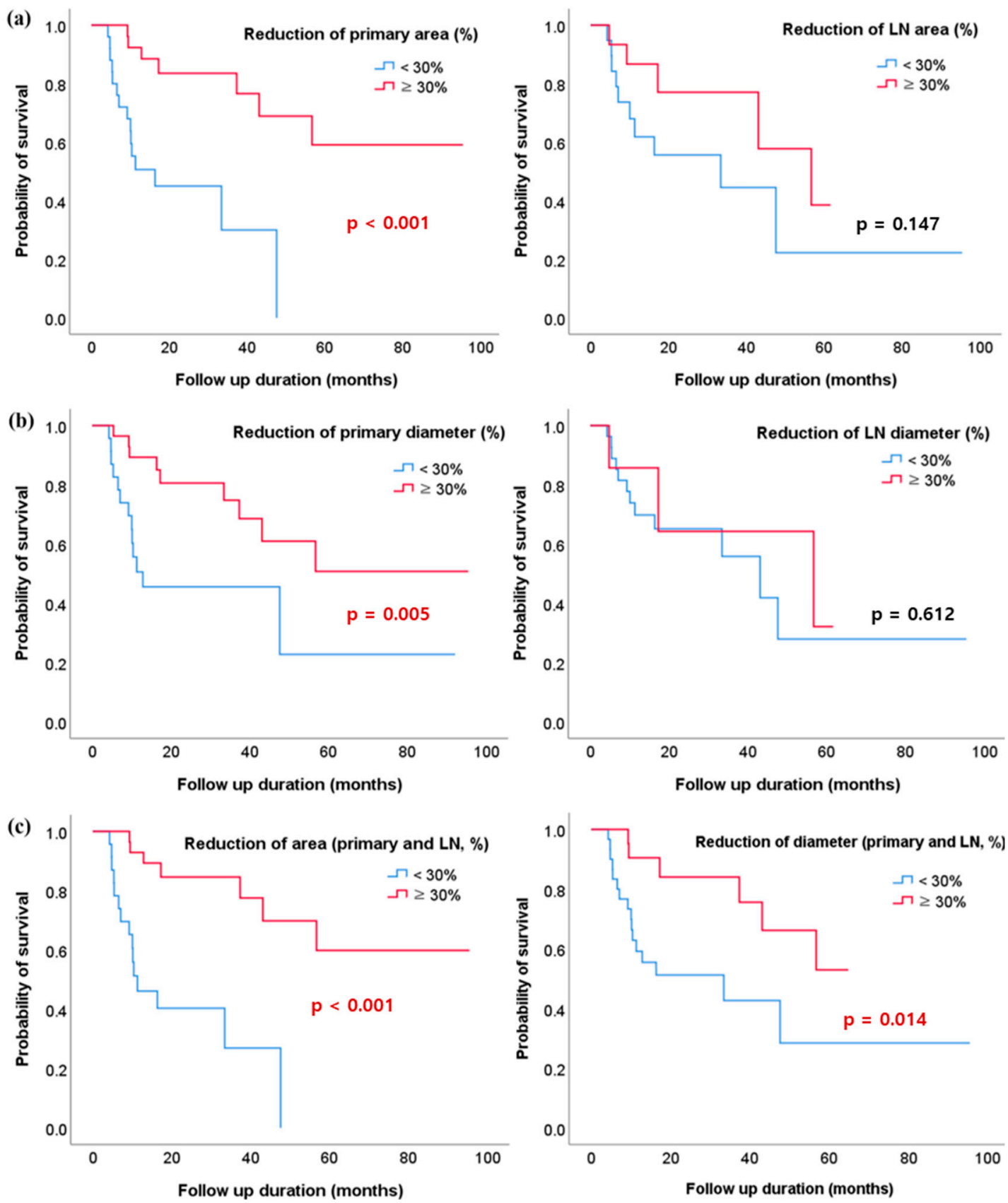

Figure 4. Kaplan-Meier analysis of overall survival (OS) rates shows a relationship between the reduction of lesion size and OS (a) Area reduction of the primary esophageal lesion/lymph node (LN) and OS rates; (b) Diameter reduction of the primary esophageal lesion/LN and OS rates; (c) Area and diameter reduction of both lesions (sum of primary esophageal lesion and $\mathrm{LN}$ ) and OS rates.

\section{Discussion}

In the present study, using adaptive $\mathrm{CT}$ images, we investigated the role of interim response in predicting survival and overall treatment response among LAESCC patients treated with dCRT. The present study showed that a favorable interim response to dCRT was associated with overall $\mathrm{CR}$ rate. The $\mathrm{CR}$ group showed significantly higher interim response than did the non-CR group, while the initial lesion area and diameter estimates were comparable between the groups. In addition, the interim response of the primary lesion was associated with OS estimates. A favorable interim response of the LNs tended to be associated with longer OS. However, this association was not statistically significant. 
Previously, dysphagia [13], hoarseness, advanced clinical stage [14], and gene expression including YAP1 and Bax [15-23] have been associated with poor prognosis in LAESCC. A multicenter study of 181 patients with esophageal cancer treated with dCRT revealed that PET response criteria in solid tumors can help evaluate therapeutic response and the risk of disease progression and death [24-30]. However, previous studies on early evaluation of dCRT response are rare. In addition, sometimes, it is difficult to evaluate the SUV value of the regional lymph node differentiated from the primary esophageal lesion. The present study has shown the benefits of an interim response evaluation in prognostication after dCRT. Adaptive CT can give the information about tumor burden, both primary esophageal lesion and LN. The use of adaptive CT scanning for interim analysis is both feasible and cost-effective, since ART is part of routine RT protocol at many institutions, helping to deliver accurate and precise dCRT doses [11].

According to multivariate analysis, the response of the primary cancer lesion showed the best correlation with CR and OS estimates. One of the strengths of this study is the investigation of the primary lesion response to treatment. Rather than being a twodimensional lesion, primary esophageal cancer is a column-shaped, three-dimensional lesion that is challenging to measure and quantify. As a result, treatment response is difficult to assess based on the RECIST criteria, which are otherwise widely used in the evaluation of solid tumors. In the present study, we measured both tumor area and maximum diameter in axial CT images, which allowed us to capture changes to the tumor burden. We emphasized the evaluation of changes to the primary esophageal tumor burden that emerged during dCRT and found a relationship between these changes and the overall treatment response and prognosis.

In the present study, the degree of interim response of the primary esophageal lesion was associated with the type of treatment failure. Specifically, we have demonstrated that the interim primary lesion area reduction during dCRT of $>15 \%$ corresponded to a higher proportion of cases with outfield treatment failure; meanwhile, the interim reduction of $<15$ corresponded to a higher proportion of cases with locoregional failure. This information may be helpful to choose treatment strategies such as intensive local treatment or systemic treatment. A large scale study with a long follow-up period may be required to show a significant correlation between the interim response and treatment failure patterns, helping physicians decide treatment strategy.

The present study has some limitations. First, this was a retrospective study, involving a relatively small number of patients. Second, only patients with adaptive CT images taken during dCRT were enrolled; as a result, the study may have been subject to selection bias, as patients with a large tumor are likely to undergo ART during dCRT. Third, the dose range for adaptive RT in the current study is quite large and a higher RT dose at adaptive $\mathrm{CT}$ scan is likely to be associated with increased response at the interim analysis. During the time period when the current study cohort underwent dCRT, patients underwent adaptive CT scans based on the initial tumor size (i.e., earlier adaptive CT scans for larger gross tumors) and symptomatic changes (i.e., improvement in swallowing difficulty). Based on the current study results, we now carry out adaptive CT scans at regular intervals of 30.6 41.4 Gy. Lastly, while ROIs were compared at the same level of axial CT image, it is difficult to confirm that the measured areas represented the entire tumor burden at the time of image acquisition. Despite these limitations, this study presents novel evidence of the predictive role of adaptive CT images, which may inform treatment strategies, including dose escalation during dCRT.

\section{Conclusions}

Interim response evaluation using adaptive $\mathrm{CT}$ images during $\mathrm{dCRT}$ may provide information regarding treatment response and prognosis among patients with LAESCC. Further studies using qualitative evaluation of ROIs, such as texture analysis in a larger population are warranted. 
Supplementary Materials: The following are available online at https:/ /www.mdpi.com/2072-669 4/13/6/1255/s1, Figure S1. Kaplan-Meier analysis of progression-free survival (PFS) rates shows a relationship between the reduction of lesion size and PFS.

Author Contributions: Conceptualization, J.-H.K.; methodology, J.G.Y., J.-H.K. and J.W.K.; software, J.G.Y., J.-H.K. and J.W.K.; validation, Y.C., I.J.L., C.G.L., J.C., Y.H.Y. and H.P.; formal analysis, J.G.Y., J.-H.K. and J.W.K.; investigation, J.G.Y., J.-H.K. and J.W.K.; resources, J.G.Y., J.-H.K. and J.W.K.; data curation, J.G.Y., J.-H.K. and J.W.K.; writing-original draft preparation, J.G.Y.; writing-review and editing, J.-H.K. and J.W.K.; visualization, J.-H.K. and J.W.K.; supervision, J.-H.K. and J.W.K.; project administration, J.-H.K. and J.W.K.; funding acquisition, J.W.K. All authors have read and agreed to the published version of the manuscript.

Funding: This research was funded by the National Research Foundation of Korea (NRF) grant funded by the Korea Government Ministry of Science and ICT (2020R1A2C1102559). and The APC was funded by the National Research Foundation of Korea (NRF) grant funded by the Korea Government Ministry of Science and ICT (2020R1A2C1102559).

Institutional Review Board Statement: The study was conducted according to the guidelines of the Declaration of Helsinki, and approved by the Institutional Review Board of Gangnam Severance Hospital (3-2018-0338).

Informed Consent Statement: Patient consent was exempted due to retrospective study.

Data Availability Statement: The data presented in this study are available on request from the corresponding author. The data are not publicly available due to privacy and ethical restrictions.

Acknowledgments: The authors thank Medical Illustration \& Design, part of the Medical Research Support Services of Yonsei University College of Medicine, for all artistic support related to this work.

Conflicts of Interest: The authors declare no conflict of interest.

\section{References}

1. Bray, F.; Ferlay, J.; Soerjomataram, I.; Siegel, R.L.; Torre, L.A.; Jemal, A. Global cancer statistics 2018: GLOBOCAN estimates of incidence and mortality worldwide for 36 cancers in 185 countries. CA Cancer J. Clin. 2018, 68, 394-424. [CrossRef]

2. Abnet, C.C.; Arnold, M.; Wei, W.-Q. Epidemiology of Esophageal Squamous Cell Carcinoma. Gastroenterology 2018, 154, 360-373. [CrossRef]

3. Lagergren, J.; Smyth, E.; Cunningham, D.; Lagergren, P. Oesophageal cancer. Lancet 2017, 390, 2383-2396. [CrossRef]

4. Berry, M.F. Esophageal cancer: Staging system and guidelines for staging and treatment. J. Thorac. Dis. 2014, 6, S289. [PubMed]

5. Smith, G.L.; Smith, B.D.; Buchholz, T.A.; Liao, Z.; Jeter, M.; Swisher, S.G.; Hofstetter, W.L.; Ajani, J.A.; McAleer, M.F.; Komaki, R.; et al. Patterns of care and locoregional treatment outcomes in older esophageal cancer patients: The SEER-Medicare Cohort. Int. J. Radiat. Oncol. Biol. Phys. 2009, 74, 482-489. [CrossRef] [PubMed]

6. Khushalani, N.I. Cancer of the esophagus and stomach. Mayo Clin. Proc. 2008, 83, 712-722. [CrossRef]

7. van Hagen, P.; Hulshof, M.C.C.M.; van Lanschot, J.J.B.; Steyerberg, E.W.; Henegouwen, M.I.v.B.; Wijnhoven, B.P.L.; Richel, D.J.; Nieuwenhuijzen, G.A.P.; Hospers, G.A.P.; Bonenkamp, J.J.; et al. Preoperative Chemoradiotherapy for Esophageal or Junctional Cancer. N. Engl. J. Med. 2012, 366, 2074-2084. [CrossRef] [PubMed]

8. Herskovic, A.; Martz, K.; Al-Sarraf, M.; Leichman, L.; Brindle, J.; Vaitkevicius, V.; Cooper, J.; Byhardt, R.; Davis, L.; Emami, B. Combined chemotherapy and radiotherapy compared with radiotherapy alone in patients with cancer of the esophagus. N. Engl. J. Med. 1992, 326, 1593-1598. [CrossRef]

9. Crehange, G.; Maingon, P.; Peignaux, K.; N'guyen, T.D.; Mirabel, X.; Marchal, C.; Verrelle, P.; Roullet, B.; Bonnetain, F.; Bedenne, L. Phase III trial of protracted compared with split-course chemoradiation for esophageal carcinoma: Federation Francophone de Cancerologie Digestive 9102. J. Clin. Oncol. 2007, 25, 4895-4901. [CrossRef]

10. Minsky, B.D.; Pajak, T.F.; Ginsberg, R.J.; Pisansky, T.M.; Martenson, J.; Komaki, R.; Okawara, G.; Rosenthal, S.A.; Kelsen, D.P. INT 0123 (Radiation Therapy Oncology Group 94-05) phase III trial of combined-modality therapy for esophageal cancer: High-dose versus standard-dose radiation therapy. J. Clin. Oncol. 2002, 20, 1167-1174. [CrossRef] [PubMed]

11. Sonke, J.J.; Aznar, M.; Rasch, C. Adaptive Radiotherapy for Anatomical Changes. Semin. Radiat. Oncol. 2019, $29,245-257$. [CrossRef] [PubMed]

12. Eisenhauer, E.A.; Therasse, P.; Bogaerts, J.; Schwartz, L.H.; Sargent, D.; Ford, R.; Dancey, J.; Arbuck, S.; Gwyther, S.; Mooney, M.; et al. New response evaluation criteria in solid tumours: Revised RECIST guideline (version 1.1). Eur. J. Cancer 2009, 45, $228-247$. [CrossRef] [PubMed] 
13. Kim, D.-E.; Kim, U.-J.; Choi, W.-Y.; Kim, M.-Y.; Kim, S.-H.; Kim, M.-J.; Shim, H.-J.; Hwang, J.-E.; Bae, W.-K.; Chung, I.-J.; et al. Clinical Prognostic Factors for Locally Advanced Esophageal Squamous Carcinoma Treated after Definitive Chemoradiotherapy. Cancer Res. Treat. 2013, 45, 276-284. [CrossRef] [PubMed]

14. Du, X.-X.; Yu, R.; Wang, Z.-F.; Du, D.-C.; Liu, Q.-Y.; Wang, R.-M.; Kang, S.-R.; Yang, H. Outcomes and prognostic factors for patients with cervical esophageal cancer undergoing definitive radiotherapy or chemoradiotherapy. Bosn. J. Basic Med. Sci. 2019, 19, 186-194. [CrossRef]

15. Dai, H.; Shao, Y.W.; Tong, X.; Wu, X.; Pang, J.; Feng, A.; Yang, Z. YAP1 amplification as a prognostic factor of definitive chemoradiotherapy in nonsurgical esophageal squamous cell carcinoma. Cancer Med. 2020, 9, 1628-1637. [CrossRef]

16. Kang, S.Y.; Han, J.H.; Lee, K.J.; Choi, J.H.; Park, J.I.; Kim, H.I.; Lee, H.W.; Jang, J.H.; Park, J.S.; Kim, H.C.; et al. Low expression of Bax predicts poor prognosis in patients with locally advanced esophageal cancer treated with definitive chemoradiotherapy. Clin. Cancer Res. 2007, 13, 4146-4153. [CrossRef]

17. Cooper, J.S.; Guo, M.D.; Herskovic, A.; Macdonald, J.S.; Martenson, J.A., Jr.; Al-Sarraf, M.; Byhardt, R.; Russell, A.H.; Beitler, J.J.; Spencer, S.; et al. Chemoradiotherapy of locally advanced esophageal cancer: Long-term follow-up of a prospective randomized trial (RTOG 85-01). Radiation Therapy Oncology Group. JAMA 1999, 281, 1623-1627. [CrossRef]

18. Maehama, T.; Nishio, M.; Otani, J.; Mak, T.W.; Suzuki, A. The role of Hippo-YAP signaling in squamous cell carcinomas. Cancer Sci. 2020, 112, 51-60. [CrossRef] [PubMed]

19. Zhou, X.; Li, Y.; Wang, W.; Wang, S.; Hou, J.; Zhang, A.; Lv, B.; Gao, C.; Yan, Z.; Pang, D.; et al. Regulation of Hippo/YAP signaling and Esophageal Squamous Carcinoma progression by an E3 ubiquitin ligase PARK2. Theranostics 2020, 10, 9443-9457. [CrossRef]

20. Qu, Y.; Zhang, L.; Wang, J.; Chen, P.; Jia, Y.; Wang, C.; Yang, W.; Wen, Z.; Song, Q.; Tan, B.; et al. Yes-associated protein (YAP) predicts poor prognosis and regulates progression of esophageal squamous cell cancer through epithelial-mesenchymal transition. Exp. Ther. Med. 2019, 18, 2993-3001. [CrossRef]

21. Sun, L.; Wei, L.; Wei, L.; Li, D. Correlation between Bax gene polymorphisms and esophagus cancer. Oncol. Lett. 2018, 16, 7097-7101. [CrossRef] [PubMed]

22. Li, L.Y.; Peng, J.D.; Zhou, W.; Qiao, H.; Deng, X.; Li, Z.H.; Li, J.D.; Fu, Y.D.; Li, S.; Sun, K.; et al. Potent hydrazone derivatives targeting esophageal cancer cells. Eur. J. Med. Chem. 2018, 148, 359-371. [CrossRef] [PubMed]

23. Joubert, A.; Maritz, C.; Joubert, F. Bax/Bcl-2 expression levels of 2-methoxyestradiol-exposed esophageal cancer cells. Biomed. Res. 2005, 26, 131-134. [CrossRef] [PubMed]

24. Kitajima, K.; Kaida, H.; Nakatani, K.; Ishibashi, M.; Morita, T.; Nakajo, M.; Tamaki, Y.; Minamimoto, R. Assessment of tumor response to definitive chemoradiotherapy and prognosis prediction in patients with esophageal cancer judged by PET response criteria in solid tumors: Multicenter study in Japan. Nucl. Med. Commun. 2020, 41, 443-451. [CrossRef]

25. Kwee, R.M. Prediction of tumor response to neoadjuvant therapy in patients with esophageal cancer with use of 18F FDG PET: A systematic review. Radiology 2010, 254, 707-717. [CrossRef]

26. Chen, Y.M.; Pan, X.F.; Tong, L.J.; Shi, Y.P.; Chen, T. Can ${ }^{18}$ F-fluorodeoxyglucose positron emission tomography predict responses to neoadjuvant therapy in oesophageal cancer patients? A meta-analysis. Nucl. Med. Commun. 2011, 32, 1005-1010. [CrossRef]

27. Schollaert, P.; Crott, R.; Bertrand, C.; D’Hondt, L.; Borght, T.V.; Krug, B. A systematic review of the predictive value of (18)FDGPET in esophageal and esophagogastric junction cancer after neoadjuvant chemoradiation on the survival outcome stratification. J. Gastrointest. Surg. 2014, 18, 894-905. [CrossRef]

28. Tani, Y.; Nakajima, M.; Kikuchi, M.; Ihara, K.; Muroi, H.; Takahashi, M.; Domeki, Y.; Okamoto, K.; Yamaguchi, S.; Sasaki, K.; et al. ${ }^{18}$ F-Fluorodeoxyglucose Positron Emission Tomography for Evaluating the Response to Neoadjuvant Chemotherapy in Advanced Esophageal Cancer. Anticancer Res. 2016, 36, 367-373.

29. Suzuki, A.; Xiao, L.; Hayashi, Y.; Blum, M.A.; Welsh, J.W.; Lin, S.H.; Lee, J.H.; Bhutani, M.S.; Weston, B.; Maru, D.M.; et al. Nomograms for prognostication of outcome in patients with esophageal and gastroesophageal carcinoma undergoing definitive chemoradiotherapy. Oncology 2012, 82, 108-113. [CrossRef]

30. Yap, W.K.; Chang, Y.C.; Hsieh, C.H.; Chao, Y.K.; Chen, C.C.; Shih, M.C.; Hung, T.M. Favorable versus unfavorable prognostic groups by post-chemoradiation FDG-PET imaging in node-positive esophageal squamous cell carcinoma patients treated with definitive chemoradiotherapy. Eur. J. Nucl. Med. Mol. Imaging 2018, 45, 689-698. [CrossRef] [PubMed] 